\title{
A categoria racionalidade médica e uma nova epistemologia em saúde
}

\section{The medical rationale category and a new epistemology in health}

Marilene Cabral do Nascimento ${ }^{1}$

Nelson Filice de Barros ${ }^{2}$

Maria Inês Nogueira ${ }^{1}$

Madel Therezinha Luz ${ }^{1}$

\footnotetext{
${ }^{1}$ Programa de Pós-

Graduação em Saúde

Coletiva, Instituto de Saúde

da Comunidade,

Universidade Federal

Fluminense. R. Marques do

Paraná 303/3, Centro.

24.033-900 Niterói RJ

Brasil.

mnascimento3@gmail.com

${ }^{2}$ Laboratório de Práticas

Alternativas,

Complementares e

Integrativas em Saúde,

Faculdade de Ciências

Médicas, Unicamp.
}

Abstract This article is an analytical report on the 20-year trajectory of the 'medical rationale' category that emerged in the early 1990s in the area of Social and Human Sciences in Health in the field of Public Health. Its objective was to study complex and therapeutic medical systems and traditional, complementary and alternative medicines. Based on a critical review of the literature, it presents some aspects of the cultural, political, institutional and social context of its emergence, as well as its main contributions and developments on a theoretical level and on social policies and practices in health. The southern epistemology concept of Boaventura de Sousa Santos is used to reflect upon the contribution of the 'medical rationale' category to the critique of the post-modern scientific rationale and to the creation of a new epistemology in health.

Key words Traditional medicine, Complementary Therapies, Culture, Epistemology, Medical rationales
Resumo $O$ artigo é um relato analítico da trajetória de 20 anos da categoria racionalidade médica, que emergiu no Campo da Saúde Coletiva, área das Ciências Sociais e Humanas em Saúde, no início da década de 1990, com o objetivo de estudar sistemas médicos complexos e terapêuticas tradicionais, complementares e alternativas. Com base em revisão crítica da literatura, apresentam-se aspectos do contexto cultural, politicoinstitucional e social de seu surgimento, como também suas principais contribuições e desdobramentos nos planos teórico e das políticas e práticas sociais em saúde. Utiliza-se o conceito de epistemologia do sul de Boaventura de Sousa Santos, para a reflexão sobre a contribuição da categoria racionalidade médica à crítica da racionalidade científica pós-moderna e à construção de uma nova epistemologia em saúde.

Palavras-chave Medicina tradicional, Terapias complementares, Cultura, Epistemologia, Racionalidades médicas 


\section{Introdução}

Este artigo é um relato analítico da trajetória de 20 anos da categoria de análise 'racionalidade médica' (RM), que emergiu no Campo da Saúde Coletiva, área das Ciências Sociais e Humanas em Saúde, no início da década de 1990. O texto apresenta alguns antecedentes, as principais contribuições e os desdobramentos desta categoria inicialmente definida no Instituto de Medicina Social da Universidade do Estado do Rio de Janeiro (IMS/UERJ), com o objetivo de estudar sistemas médicos complexos e terapêuticas tradicionais e complementares ${ }^{1}$. Com base no conceito de 'epistemologia do sul' de Boaventura de Sousa Santos $^{2}$, trazemos uma reflexão sobre a contribuição da categoria RM à crítica da racionalidade científica pós-moderna e à construção de uma nova epistemologia em saúde.

\section{Antecedentes e contexto de criação}

O contexto que antecedeu a formulação da categoria RM foi marcado pelo fortalecimento do discurso em favor da preservação e valorização da natureza. No âmbito internacional, os movimentos de contracultura de tendência antitecnológica, nos EUA e Europa, ao final dos anos 60 , resistiam à desvalorização do mundo natural em prol de outro, construído pela ciência e a técnica, e fortaleciam noções e conceitos ligados à ecologia. No caso específico da relação saúdemedicina, tais movimentos deram espaço a uma proposta ativa de promoção da saúde (ao invés do combater doenças, característico da medicina científica), e a um conjunto de sistemas terapêuticos e práticas de medicação e cuidados tendentes ao naturismo. O naturismo significava, nesse caso, "não apenas a rejeição da medicina especializada e tecnificada, por invasiva e iatrogênica, portanto antinatural, mas também a afirmação da força curativa da natureza e da eficácia das terapêuticas dela provenientes"”.

A crítica à farmacologia química como base da terapêutica médica, formulada ao longo dos anos 70 por autores como Dupuy e Karsenty ${ }^{4}$, Illich $^{5}$, Foucault ${ }^{6}$ e Clavreul $^{7}$, complementavam o discurso naturista em saúde. Entre outros aspectos, estes autores destacaram a iatrogenia médica e farmacêutica; a medicalização social como instância de dominação política e controle dos cidadãos; o deslocamento da saúde como participação e possibilidade de atuação na ordem social à suportabilidade de uma ordem imposta pela lógica de produção e mercado; a in- terdição da ideia de bem-estar e prazer pela normalidade medicalizada; o reducionismo biologicista da medicina e suas consequências, como a limitação do sofrimento humano a dimensões estanques, tecnologicamente especializadas ${ }^{8}$.

$\mathrm{Na}$ esfera institucional, a Conferência das Nações Unidas sobre o Meio Ambiente Humano, realizada em Estocolmo em 1972, foi um marco na defesa do "ambiente humano para as atuais e futuras gerações”. A resistência à degradação da natureza passou a considerar crescentemente o meio ambiente em seu sentido amplo - natural, social e biológico -, em defesa da qualidade de vida e da saúde. Vinte anos depois, a Conferência das Nações Unidas sobre Meio Ambiente e Desenvolvimento, realizada no Rio de Janeiro (Eco 92), consagrou o conceito de desenvolvimento sustentável, considerando seus aspectos econômico, social e ambiental, e propôs a Agenda 21, um instrumento para repensar o planejamento em âmbito global, nacional e local, tendo como meta um novo paradigma econômico e civilizatório que valorize a preservação e o fomento dos ecossistemas do planeta, da vida e da saúde.

No campo específico da saúde, a Conferência Internacional de Alma-Ata, realizada na antiga União Soviética (URSS) em 1978, afirmou os cuidados primários como elemento chave para se chegar a um nível aceitável de saúde. Ao defender a realização de medidas sanitárias e sociais, preconizou a legitimação de práticas tradicionais, alternativas ou complementares. O então diretorgeral da Organização Mundial de Saúde declarou nesta conferência a insuficiência da medicina tecnológica e especialista para a resolução de problemas de saúde de dois terços da humanidade.

Em 1986, a I Conferência Internacional sobre Promoção da Saúde realizada em Ottawa, Canadá, veio a afirmar que não apenas os fatores biológicos, mas também os políticos, econômicos, sociais, culturais, de meio ambiente e de conduta podem intervir a favor ou contra a saúde. Entre outros aspectos, a Carta de Ottawa defendeu que os serviços de saúde adotem "uma postura abrangente, que perceba e respeite as peculiaridades culturais", e incentivem "a participação e a colaboração de outros setores, outras disciplinas e, mais importante, da própria comunidade”.

No Brasil, foi criado o Sistema Nacional de Meio Ambiente em 1981, onde se defendeu a utilização racional dos recursos ambientais em condições propícias à saúde e à qualidade de vida. Em 1986, o relatório final da VIII Conferência Nacional de Saúde propôs “a introdução de práticas 
alternativas de assistência à saúde no âmbito dos serviços de saúde, possibilitando ao usuário o direito democrático de escolher a terapêutica preferida". O texto constitucional de criação do Sistema Único de Saúde (SUS), em 1988, não faz referência direta a práticas tradicionais e complementares em saúde, mas afirma o "atendimento integral, com prioridade para as atividades preventivas" e a participação da comunidade.

Quanto às práticas sociais, os anos 70 e principalmente os 80 trouxeram um aumento da demanda por outras formas de bens e serviços de saúde, entre amplos setores das populações urbanas. Ao lado da importação de antigos sistemas médicos orientais, como a medicina ayurvédica e a tradicional chinesa, observou-se a reabilitação de terapêuticas populares, como as xamânicas ou as ligadas às religiões afro-indígenas. A homeopatia foi retomada como medicina alternativa. Junto a ela, sob a denominação de terapias alternativas, tradicionais, holísticas, integrais, naturais, doces, energéticas ou complementares, diversas formas de cuidado conquistavam expressão no campo da saúde. Por outro lado, estudos socioantropológicos nacionais abordavam a temática de práticas tradicionais e complementares principalmente através do enfoque da medicina popular e religiosa, praticada por rezadores, curandeiros, especialistas em ervas, parteiras, entre outros, como no livro de Maria Andréa Loyola, "Médicos e Curandeiros", publicado em $1984^{9}$. A formulação da categoria RM em 1992 veio inovar esta abordagem.

O projeto RM propôs a comparação das medicinas homeopática, tradicional chinesa, ayurvédica e ocidental contemporânea, também denominada biomedicina. A hipótese central da primeira fase do projeto é que existe mais de uma racionalidade médica, contrariamente ao senso comum ocidental que admite somente a biomedicina como portadora, no sentido científico do termo. O projeto buscava demonstrar que distintas racionalidades médicas efetivamente coexistem na cultura atual.

\section{Dimensões como signo de comensurabilidade}

A categoria RM foi construída em perspectiva tendencial histórica, ao estilo de um tipo ideal segundo o sociólogo Max Weber (1864-1920). Sua aplicação permitiu constatar a presença, com maior ou menor grau de explicitação teórica, de traços ou dimensões fundamentais dos sistemas médicos estudados. Dimensões estas que nunca chegam a se realizar de forma acabada, por terem a capacidade de serem modificadas historicamente pela ação dos agentes sociais. Trata-se de cinco dimensões básicas, estruturadas em termos teóricos, práticos e simbólicos, conforme se segue:

1) Morfologia humana (na biomedicina, anatomia), que define a estrutura e a forma de organização do corpo;

2) Dinâmica vital humana (na biomedicina, fisiologia), que define o movimento da vitalidade, seu equilíbrio ou desequilíbrio no corpo, suas origens ou causas;

3) Doutrina médica que define, em cada sistema, o que é o processo saúde-doença, o que é a doença ou adoecimento, em suas origens ou causas, o que é passível de tratar ou curar (na biomedicina, o que pertence ou não à clínica);

4) Sistema de diagnose, pelo qual se determina se há ou não um processo mórbido, sua natureza, fase e evolução provável, origem ou causa,

5) Sistema terapêutico, pelo qual se determinam as formas de intervenção adequadas a cada processo mórbido (ou doença) identificado pela diagnose.

De acordo com o estudo, pode ser denominada racionalidade médica apenas um sistema médico complexo estruturado segundo estas cinco dimensões, sistematizadas em maior ou menor grau. Ao final da primeira fase da pesquisa, constatou-se a presença de uma sexta dimensão, que embasa teórica e simbolicamente as outras cinco, denominada cosmologia. Seu caráter elaborado e sistemático qualifica as raízes filosóficas das racionalidades médicas. A visão cosmológica da biomedicina está sustentada na física clássica newtoniana e na metáfora cartesiana do corpo como máquina direcionada pela mente. Nas medicinas ayurvédica e tradicional chinesa, a cosmologia está enraizada em filosofias religiosas, como o conhecimento védico na Índia e o taoísmo chinês.

A presença desta sexta dimensão permitiu a constatação de limites na racionalidade dos sistemas, uma vez que a cosmologia, própria da cultura em que se insere, é enraizada em um universo simbólico de sentidos que incluem imagens, metáforas, representações e mesmo concepções que são parte de um imaginário social irredutível ao plano de proposições teóricas e empíricas demonstráveis pelo método científi$\mathrm{CO}^{10}$. Não obstante, as racionalidades médicas têm em comum o fato de se constituírem em saberes/ práticas doutos, cujas concepções e proposições se pretendem demonstráveis empiricamente, seja 
por meio de tecnologias cientificamente avançadas, seja por demonstração empírica tradicional. Trata-se também de sistemas institucionalizados, seja na cultura ocidental, seja em sua cultura de origem (China e Índia, nos casos estudados), às vezes nas duas, e ensinados em instituições acadêmicas legitimadas, embora inseridos no sistema global capitalista, onde prevalece a hierarquização dos saberes, juntamente com a de sistemas econômicos e políticos.

As seis dimensões apontadas se constituem condição necessária e suficiente para estarmos em presença de uma racionalidade médica, sendo base de comparação entre as diversas pesquisadas (Quadro 1).

É importante destacar que não se pretendeu comparar sistemas culturais diferentes, mas distintos sistemas médicos implicados numa mesma cultura, a atual, definida como pós-moderna, ao mesmo tempo unificada, fragmentária e sincrética. Não houve também uma tomada de posição quanto ao valor ético ou epistemológico dos sistemas médicos definidos como racionalidade médica. Ao considerar apenas sistemas médicos complexos estruturados segundo as seis dimensões, o estudo excluiu em sua primeira fase o que se denomina práticas terapêuticas integrativas e complementares.

A primeira fase do estudo, de caráter teórico conceitual, destacou também a presença de dois paradigmas em saúde: o biomédico (ou da normalidade-patologia) e o vitalista (ou da vitalidade-energia). O paradigma biomédico enfatiza concepções materialistas, mecanicistas, centradas na doença e no controle do corpo biológico e social, compatíveis com a visão de controle sobre a na- tureza presente na ciência contemporânea. Esta visão tem raízes no período Renascentista e na ascensão do discurso da ciência, quando o real foi associado ao racional, e o homem se percebeu como herdeiro de Deus, mais senhor da natureza do que parte dela. Neste discurso, a natureza foi separada do sagrado e do humano, passou a ser objeto de conhecimento, sobretudo com o intuito de ser controlada com fins utilitários $^{11}$. A tecnologia é a ferramenta para a execução deste projeto. O complexo médico-industrial e a concepção de cura enquanto controle de doenças integram e ilustram esta trajetória.

O paradigma vitalista, centrado na saúde e na busca de harmonia da pessoa com seu meio ambiente natural e social, valoriza a subjetividade individual, a prevenção e a promoção da saúde e a integralidade do cuidado ${ }^{12}$. Mostra-se compatível a anseios de preservação e sustentabilidade em seu sentido amplo, nos níveis biológico, social e natural; cujas raízes, presentes em antigas tradições culturais, são ressignificadas e conquistam espaço crescente na atualidade desde os anos 60, como portadoras do ideário da contracultura.

A fase inicial do estudo identificou ainda no interior de cada racionalidade a coexistência, não sem conflito, de duas formas de apreensão/interpretação: a primeira de caráter teórico, regida pela razão; a segunda, de natureza prática, regida pela experiência singular, a sensibilidade e a intuição proporcionadas pela percepção do terapeuta ${ }^{13}$. O conhecimento prático faz uso da razão, mas em função da eficácia a ser obtida em sua intervenção, sendo, portanto, um conhecimento ativo. Estas formas de conhecimento são potencialmente complementares, embora uma delas possa ga-

Quadro 1. Resumo comparativo das Racionalidades Médicas.

\begin{tabular}{|c|c|c|c|c|c|}
\hline $\begin{array}{c}\text { Racionalidades } \\
\text { médicas }\end{array}$ & Cosmologia & Morfologia & $\begin{array}{c}\text { Dinâmica vital } \\
\text { ("Fisiologia") }\end{array}$ & $\begin{array}{c}\text { Sistema } \\
\text { diagnóstico }\end{array}$ & Sistema terapêutico \\
\hline $\begin{array}{c}\text { Medicina Ocidental } \\
\text { Contemporânea }\end{array}$ & $\begin{array}{c}\text { Traços } \\
\text { fundamentais }\end{array}$ & $\begin{array}{c}\text { Traços } \\
\text { básicos }\end{array}$ & $\begin{array}{c}\text { Aspectos } \\
\text { principais }\end{array}$ & $\begin{array}{c}\text { Aspectos } \\
\text { principais }\end{array}$ & $\begin{array}{c}\text { Formas principais de } \\
\text { intervenção }\end{array}$ \\
\hline $\begin{array}{c}\text { Medicina } \\
\text { Homeopática }\end{array}$ & $\begin{array}{c}\text { Traços } \\
\text { fundamentais }\end{array}$ & $\begin{array}{c}\text { Traços } \\
\text { básicos }\end{array}$ & $\begin{array}{c}\text { Aspectos } \\
\text { principais }\end{array}$ & $\begin{array}{c}\text { Aspectos } \\
\text { principais }\end{array}$ & $\begin{array}{c}\text { Formas principais de } \\
\text { intervenção }\end{array}$ \\
\hline $\begin{array}{c}\text { Medicina } \\
\text { Tradicional Chinesa }\end{array}$ & $\begin{array}{c}\text { Traços } \\
\text { fundamentais }\end{array}$ & $\begin{array}{c}\text { Traços } \\
\text { básicos }\end{array}$ & $\begin{array}{c}\text { Aspectos } \\
\text { principais }\end{array}$ & $\begin{array}{c}\text { Aspectos } \\
\text { principais }\end{array}$ & $\begin{array}{c}\text { Formas principais de } \\
\text { intervenção }\end{array}$ \\
\hline $\begin{array}{c}\text { Medicina } \\
\text { Ayurvédica }\end{array}$ & $\begin{array}{c}\text { Traços } \\
\text { fundamentais }\end{array}$ & $\begin{array}{c}\text { Traços } \\
\text { básicos }\end{array}$ & $\begin{array}{c}\text { Aspectos } \\
\text { principais }\end{array}$ & $\begin{array}{c}\text { Aspectos } \\
\text { principais }\end{array}$ & $\begin{array}{c}\text { Formas principais de } \\
\text { intervenção }\end{array}$ \\
\hline
\end{tabular}

Fonte: dados compilados pelos autores. 
nhar proeminência em sistemas médicos ou contextos sócio-históricos específicos.

\section{Compartilhamento de representações e paradigmas entre profissionais e usuários dos serviços de saúde}

A segunda fase do projeto RM teve início em 1994 e foi desenvolvida junto a profissionais e usuários de serviços de saúde da rede pública do município do Rio de Janeiro, através de entrevista e observação direta. Analisou representações e sentidos atribuídos à doença, saúde, tratamento, cura, corpo, relação corpo-mente, entre outras, em médicos ou terapeutas e pacientes de três racionalidades médicas (biomedicina, homeopatia e medicina tradicional chinesa), bem como verificou se estas representações eram partilhadas por profissionais e clientelas, ou não. A medicina ayurvédica não pode ser acompanhada porque não havia serviços públicos desta racionalidade médica no Rio de Janeiro.

A hipótese nuclear do projeto era que a clientela e os profissionais de um determinado sistema médico tendem a partilhar paradigma e representações de sua racionalidade, e que este partilhar cultural tende a facilitar as relações médico-paciente, ou terapeuta-paciente, facilitando assim o processo terapêutico.

Observou-se que o compartilhamento de representações e paradigmas era claro quando se tratava da homeopatia - identidade de representações corpo-mente como totalidade indissociável, de equilíbrio como sinônimo de saúde, de energia como fonte de vitalidade, e de cura como um processo subjetivo de harmonização ${ }^{14,15}$. Quando se tratava da biomedicina, o compartilhamento era parcial, com identificação em relação à representação do corpo como máquina composta de 'peças' ou partes articuladas, do adoecimento como incapacidade de trabalhar ou mover-se, e de cura como retorno à normalidade sintomática e à vida ativa ${ }^{16}$. A valorização de aspectos subjetivos relacionados ao processo de adoecimento, entretanto, embora frequente em representações da clientela, não encontravam eco correspondente nos profissionais da biomedicina.

$\mathrm{Na}$ medicina tradicional chinesa (MTC), o compartilhamento de representações se mostrou menos presente, provavelmente devido ao lugar de auxiliar terapêutico que esse sistema ocupava em relação à biomedicina. As representações dos terapeutas, os que eram formados na visão holista da MTC, diferiam das de sua clientela, que tendia a ver na acupuntura um procedimento quase mecânico, que produz resultado sobre a dor ou inflamação. Este tipo de representação, presente na clientela, seria induzido pela própria racionalidade da biomedicina ${ }^{17}$. Em todos os casos, entretanto, observou-se que independente do sistema médico estudado, as representações não se mostram 'puras' do ponto de vista de sentidos e significados atribuídos, isto é, não se restringem ao universo da racionalidade do sistema médico.

Tal constatação expressa a presença de hibridismo e ecletismo, quando não de sincretismo na simbologia contemporânea ${ }^{18}$ sobre corpo, saúde, doença, tratamento, cura etc. As representações do corpo como máquina coexistem com as bioenergéticas (o corpo como uma organização mais ou menos equilibrada de níveis de energia circulante) em uma mesma pessoa, cliente ou terapeuta. A clientela transita de uma a outra racionalidade médica de acordo com a variação de seu adoecimento e dos sentidos que a ele atribui, enquanto os médicos e terapeutas conjugam procedimentos terapêuticos ou diagnósticos de mais de uma racionalidade em seu agir cotidiano.

\section{Práticas terapêuticas e de saúde}

A terceira fase do projeto RM, iniciada em 1997, centrada nas práticas terapêuticas, constatou a diferença existente entre racionalidades médicas e práticas terapêuticas. Estas, embora possam ser elementos de uma dimensão de uma racionalidade médica específica, são frequentemente utilizadas de forma isolada, deslocadas de seu contexto de significados para outro, obedecendo mais a uma lógica empírica de eficácia no estilo da biomedicina, que a uma coerência teórica dos sistemas. Propiciam assim o hibridismo e o sincretismo das práticas no cuidado à saúde.

No Brasil, o Ministério da Saúde optou pela terminologia PIC (práticas integrativas e complementares), que engloba tanto as racionalidades médicas vitalistas quanto as práticas terapêuticas ditas integrativas e complementares em saúde. Tais práticas estão cada vez mais ao alcance de usuários dos serviços públicos, em função do Sistema Único de Saúde (SUS) e, mais recentemente, da Política Nacional de Práticas Integrativas e Complementares (PNPIC), da qual trataremos adiante. Além das já tradicionais homeopatia, acupuntura e fitoterapia, há um aumento gradual na presença de diferentes práticas de abordagem corporal ou psico-corporal, tais como tai chi chuan, lian gong, lian kun, chi gong, do-in, tui-na, ioga, reiki, meditação, terapia comunitária, biodança, osteopatia, termalismo/crenoterapia ${ }^{19,20}$. 
Estas práticas terapêuticas estão basicamente associadas à intervenção em processos de adoecimento ou mal-estar de indivíduos e grupos, de caráter 'objetivo' (patologias identificáveis pela biomedicina), como também situações de estresse e sofrimento psíquico. Algumas utilizam as artes como parte constitutiva de seus procedimentos: música, teatro, artes plásticas, dança. Preenchem lacunas do sistema biomédico quanto à resolutividade terapêutica de seus serviços; ao lado disto, sustentam sentidos, significados e valores sociais diante do sofrimento, do adoecimento, como também do tratamento e da cura de doenças, distintos dos dominantes. Estes valores tendem a favorecer a autonomia das pessoas na busca de uma vida mais harmoniosa, isto é, equilibrada mental e fisicamente, menos competitiva ou agressiva, e mais solidária no plano familiar e social.

As Práticas Integrativas e Complementares (PIC) expressam, assim, a complexificação do campo da saúde acompanhada de uma multiplicação de sujeitos implicados nas práticas terapêuticas, e integram o processo de medicalização da saúde como a gestão social do sofrimento e do adoecer. É importante ressaltar, entretanto, que de acordo com o referencial teórico utilizado neste artigo, as PIC não são racionalidades médicas. A utilização da categoria RM em diferentes núcleos de pesquisa, nas diversas regiões do país, tem contribuído para expandir a reflexão desta temática. Não obstante, tem-se observado algumas apropriações ou usos inadequados, que levam a interpretações e análises equivocadas, sobretudo quando se aplica a categoria na pesquisa de práticas integrativas e complementares, buscando-se identificar nestas as dimensões que caracterizam os sistemas médicos complexos. Cabe aqui alertar para o uso impróprio desta ferramenta analítica, considerando suas premissas e possibilidades interpretativas.

Mas além de práticas terapêuticas, foi possível verificar no desenvolvimento da terceira fase do projeto RM, novas práticas de saúde, que valorizam a tríade beleza-vigor-juventude, tomando como referencial de saúde a boa forma (fitness), identificada à beleza das formas, ou o bemestar (wellness), geralmente visto como estar equilibrado, ou harmonizado, ou ainda 'bem consigo mesmo' ${ }^{21}$.

O fisiculturismo, associado ao fitness, envolve a musculação e diversas formas de ginástica localizada e aeróbica, podendo incluir alguns esportes, sobretudo os de risco e aventura, e algumas artes marciais ou lutas, como judô e caratê. Tem lugar privilegiado nas academias de ginásti- ca e reverencia valores de vigor, beleza e juventude como sinônimos de vitalidade, portanto saúde. É frequentemente orientado por concepções centrais do individualismo atual - o uso do corpo como forma de obtenção de status social, o consumismo como valor de prestígio e diferenciação social e o sucesso como valor fim para a vida; desta perspectiva expressa o triunfo de valores do capitalismo entre jovens da classe média das grandes metrópoles, seus principais praticantes $^{22}$. Mas à medida que se avança na faixa etária, observa-se uma maior diversificação de práticas, que contemplam, além das mencionadas acima, o alongamento, a ioga, o pilates, o tai chi chuan, a dança de salão, entre outras, frequentemente adotadas por aconselhamento médico, seja por causa de doenças crônicas (hipertensão, diabetes, artrites, osteoporose, obesidade etc.), seja por problemas emocionais (estresse, depressão, baixa autoestima, isolamento social etc.). Na faixa etária dos 40 anos em diante, os praticantes estão buscando cada vez mais conservar ou recuperar a saúde, o que inclui os valores de conservação da juventude e beleza e também a busca de bem-estar.

É possível afirmar, a partir das entrevistas e observações realizadas na terceira fase do projeto, que há uma diversidade de sentidos, significados e valores associados à multiplicidade de práticas e praticantes atuais em saúde. Alguns estão nitidamente associados à cultura capitalista hegemônica e seus valores, como o culto individualista à beleza corpórea, ao consumo de bens materiais como forma de diferenciação, à competição como norma de vida e meio de alcançar o sucesso, considerado como um valor fim. Outros, mais relacionados a maneiras de estar consigo mesmo e com outros, se não solidárias, ao menos cordiais e amigáveis. Assim sendo, não apenas valores fisiculturistas ou relativos ao paradigma doençasaúde estão presentes nestas práticas, mas também ligados ao bem estar pessoal, à modificação de estados emocionais, à maior disposição para o trabalho e a convivência familiar e social, e à recuperação da alegria de viver ${ }^{13,22}$.

Em síntese, as concepções presentes nas práticas de saúde contemporâneas partilham o modelo preventivista (prevenir, amenizar ou ao menos deter o desenvolvimento de enfermidades crônicas), o modelo promocionista (manter a saúde, não adoecer), o modelo estético (beleza, vigor, juventude) e o modelo vitalista (expansão da vitalidade, equilíbrio, harmonia das dimensões da vida), podendo haver dominância de um ou mais modelos de acordo com especificidades 
de cada prática, de contextos e praticantes correspondentes.

\section{Pesquisa e ensino de racionalidades médicas e práticas em saúde}

A produção científica sobre o tema das racionalidades médicas teve início no final da década de 80 e se consolidou como atividade de pesquisa coletiva a partir da proposição da categoria RM em 1992, tendo um crescimento significativo nos anos seguintes (Tabela 1).

Estes números consideram apenas a produção dos integrantes do grupo de pesquisa vinculado ao Conselho Nacional de Pesquisa e Tecnologia $(\mathrm{CNPq})$ e intitulado atualmente Racionalidades em Saúde: Sistemas Médicos e Práticas Complementares e Integrativas. O grupo conta com núcleos de pesquisadores em diferentes instituições de ensino e pesquisa em Florianópolis (SC), Campinas (SP), Rio de Janeiro (RJ), Niterói (RJ) e Juiz de Fora (MG). Contudo, outros pesquisadores não diretamente vinculados utilizam a categoria RM em seus estudos e publicações científicas, inclusive fora do país, como é o caso de Portugal, onde alguns artigos resultantes de teses de doutorado trabalham com essa categoria ${ }^{23-27}$.

Em sua quarta e atual fase, o projeto RM descreveu a Medicina Antroposófica como racionalidade médica ${ }^{28}$ coexistindo na sociedade atual no campo da saúde, juntamente com outras racionalidades já estudadas na primeira fase do grupo de pesquisa.

A pesquisa 'Racionalidades Médicas e Formação em Saúde' encontra-se em andamento no Programa de Pós-graduação em Saúde Coletiva (PPGSC) da Universidade Federal Fluminense, que sedia o grupo Racionalidades em Saúde: Sistemas Médicos e Práticas Complementares e In- tegrativas desde 2010. Neste estudo, busca-se analisar a presença da homeopatia e da medicina tradicional chinesa no ensino técnico e universitário (graduação e pós-graduação) em saúde, assim como identificar inovações no ensino da biomedicina, e relacioná-las a premissas humanizantes trazidas pela área da Saúde Coletiva, tais como ampliação da clínica, acolhimento, cuidado, integralidade e promoção da saúde.

Entende-se que a formação em distintas racionalidades médicas e práticas de saúde seja fundamental para o seu avanço sustentável, com segurança, qualidade e eficácia no SUS, de forma a garantir o direito da população ao cuidado integral e à escolha do modelo terapêutico, de acordo com as concepções de saúde dos cidadãos e grupos sociais, como também das possibilidades terapêuticas envolvidas.

\section{Legitimação, institucionalização \\ e legalização de racionalidades médicas \\ e práticas integrativas e complementares em saúde}

A expressiva produção e repercussão de estudos acadêmicos com a utilização da categoria RM tem informado o debate entre profissionais e gestores sobre a legitimação, institucionalização e legalização das racionalidades médicas e práticas integrativas e complementares em saúde.

Os anos 80 marcaram o começo da trajetória de institucionalização das PIC nos serviços públicos de saúde no município do Rio de Janeiro, impulsionada principalmente pela acupuntura, cujo processo de legitimação e legalização tem liderado e ao mesmo tempo exemplificado o percurso das práticas complementares no Brasil. Após uma bem sucedida estratégia de divulgação e legitimação através da mídia impressa, teve início uma

Tabela 1. Distribuição da produção científica do grupo Racionalidades em Saúde, da década de 1980 até o ano de 2011. Brasil.

\begin{tabular}{lcccrr}
\hline & & & & \multicolumn{2}{c}{ Total } \\
\cline { 5 - 6 } \multicolumn{1}{c}{ Produção RS } & Década 80 & Década 90 & $\mathbf{2 0 0 0 - 2 0 1 1}$ & No & \% \\
\hline Livros & 1 & 10 & 37 & 48 & 10 \\
Capítulos de Livros & - & 15 & 107 & 122 & 26 \\
Artigos & 5 & 57 & 182 & 244 & 51 \\
Dissertações & - & 12 & 25 & 37 & 8 \\
Teses & - & 6 & 19 & 25 & 5 \\
Total & 6 & 100 & 370 & 476 & 100 \\
\hline
\end{tabular}

Fontes: 1. Arquivos do grupo "Racionalidades Médicas e Práticas em Saúde". 2. Informações contidas na Plataforma LATTES do CNPq a partir do diretório do grupo de pesquisa "Racionalidades em saúde: sistemas médicos e práticas e complementares integrativas". 
experiência piloto no Hospital Municipal Paulino Werneck. Pouco depois, em 1984, a acupuntura passou a integrar o atendimento nas chamadas clínicas da dor, em quatro hospitais do município. Em 1987, foi criado o Serviço de Medicina Alternativa na Secretaria Municipal de Saúde, com o objetivo de oferecer à população serviços de acupuntura, homeopatia e fitoterapia ${ }^{29,30}$.

Entretanto, duas propostas dividiam os acupunturistas: a que pleiteava a exclusividade médica para o exercício desta terapêutica, com a consequente interdição da prática de profissionais não médicos; e a que defendia o seu exercício também por não médicos, desde que devidamente habilitados.

Os médicos que já nessa fase inicial aderiram à prática da acupuntura exerceram papel importante na introdução desta terapêutica na rede pública de saúde, como também na sua receptividade pela população. Muitas vezes frustrados com as possibilidades oferecidas em sua prática profissional, voltaram-se para o estudo da medicina chinesa, encontrando nela instrumentos eficazes para o desempenho de suas funções. Porém, os conselhos de medicina não reconheciam a acupuntura enquanto prática terapêutica, associando-a ao misticismo e ao charlatanismo.

Este fato contribuiu para que a maioria dos acupunturistas fosse composta por profissionais não médicos, havendo entre eles fisioterapeutas, enfermeiros e outros profissionais da área da saúde, inclusive de nível médio. Apenas em 1992, o Conselho Federal de Medicina reconheceu a acupuntura como ato médico e três anos mais tarde veio a designá-la uma especialidade (Resolução $1455 / 95)^{31}$. Nessa ocasião, foi desencadeada uma ampla campanha na mídia em defesa do monopólio médico no exercício da acupuntura, como já acontecia com a homeopatia, reconhecida como especialidade em 1980, e desde então praticada exclusivamente por esta categoria.

A polêmica entre médicos e não médicos para o exercício da acupuntura persiste até os dias atuais, com importantes repercussões no processo de institucionalização e legalização desta prática e também de outras modalidades terapêuticas integrativas e complementares. Os anos 90 marcaram um acirramento nesta polêmica.

O processo de incorporação da acupuntura pela categoria médica apresenta uma característica básica de complementaridade com a medicina ocidental contemporânea (ou biomedicina), configurando-se um estilo eclético nas formas de atuação. Entretanto, observa-se uma tendência entre os profissionais médicos a não conside- rar suficientemente o sistema coerente e integrado do qual se origina e faz parte a acupuntura, ou seja, um sistema médico que traz a noção de continuidade entre os diferentes planos da existência (psicobiológicos, sociais e espirituais) na produção da saúde, da doença e da cura, e no qual a pessoa é entendia como integralidade viva, em sua relação com o meio natural e social. Além do peso da formação biomédica, características sociais, econômicas e culturais da demanda e dos profissionais têm contribuído para uma recriação da prática da acupuntura no meio médico ${ }^{32,33}$.

Neste contexto, a proposição da categoria RM, baseada na hipótese de existência de diferentes racionalidades médicas e sua coexistência efetiva na cultura atual, passou a informar o debate não apenas nos centros acadêmicos de pesquisa, mas também nas instituições de saúde, seja entre os profissionais, seja na produção de normas e, mais tarde, legislação específica sobre a acupuntura e outras práticas terapêuticas que partilham o paradigma vitalista.

A categoria RM passou a ser utilizada com uma perspectiva política, na afirmação da legitimidade de diferentes sistemas médicos complexos e na defesa de sua integração nos serviços públicos como prática multiprofissional, de forma integrativa e complementar. A Política Nacional de Práticas Integrativas e Complementares, editada em 2006, adotou a expressão 'sistemas médicos complexos', associando-a aos estudos do projeto RM através da referência direta a algumas de suas publicações.

Através da PNPIC, o Ministério da Saúde passou a preconizar o desenvolvimento da MTCAcupuntura "em caráter multiprofissional, para as categorias profissionais presentes no SUS e em consonância com o nível de atenção”. A PNPIC preconiza também a implementação de mais dois sistemas médicos complexos no SUS: a homeopatia e a medicina antroposófica. Entre as práticas terapêuticas, são contempladas as plantas medicinais e a fitoterapia, o termalismo social-crenoterapia, como também um conjunto de práticas dentro da abordagem terapêutica específica da MTC: lian gong, chi gong, tui-na, taichi-chuan, plantas medicinais, orientação alimentar e meditação.

\section{Contribuição a uma nova epistemologia em medicina e saúde}

Sistemas médicos tradicionais e modernos estão alinhados em uma interação, às vezes conflituosa, às vezes de maneira pacífica e mais ou 
menos integrada. Sua cooperação, mesmo que ocasional, tem contribuído para acelerar a assimilação mútua, de modo híbrido ou sincrético, tanto em termos teóricos como empíricos. As relações de continuidade, ruptura e hibridização e os processos de negociação entre diferentes sistemas do desenvolvimento cultural são hoje um dos maiores desafios das ciências sociais no campo da saúde. Os conflitos e as formas de coexistência, em uma comunicação multicontextual, multiétnica, migrante, composta de elementos multiculturais, tornam-se um relato reconstruído incessantemente, de modos diversos, nos desiguais campos de produção, comunicação e apropriação da cultura ${ }^{34}$.

Ao propor a expressão 'epistemologia do sul', Boaventura de Sousa Santos ${ }^{2,35,36}$ afirmou que a colonização epistêmica persiste e gera profundas contradições, com uma divisão radical entre saberes que atribui à ciência moderna o monopólio universal de distinção entre o verdadeiro e o falso. A persistência da dominação epistêmica de matriz colonial, para além do processo das independências políticas, exige uma revisão crítica de conceitos hegemonicamente definidos pela racionalidade moderna a partir de uma perspectiva e condição de subalternidade. Segundo ele, uma das batalhas políticas mais importantes do século XXI é travada, sem dúvida, em torno do conhecimen- to. $\mathrm{O}$ desafio à hegemonia cultural tem resultado numa abertura à diversidade de saberes, diferentes lógicas e formas de pensar, que exigem a possibilidade de diálogo e comunicação entre culturas, quer numa interação com a ciência moderna, quer para além desta, no sentido de recuperar saberes e práticas de grupos sociais que, por via do capitalismo e colonialismo, foram subalternizados, marginalizados e desacreditados.

De acordo com Meneses ${ }^{37}$, é necessário, entretanto, fugir do risco de "reificações funcionalistas da tradição (...) como forma de contrapor a racionalidade moderna a outros saberes e experiências considerados tradicionais porque anteriores à modernidade". Este risco "limita a possibilidade crítica e analítica da estrutura conceitual sobre a qual assentam as concepções ideológicas da modernidade". O desafio, portanto, é reconfigurar sentidos e explicações dominantes e construir uma nova narrativa teórica, como forma de alargar e qualificar a epistemologia do século XXI. Desta perspectiva, a categoria RM pode se apresentar como uma contribuição da "epistemologia do sul" que permite revisitar diferentes saberes e práticas em saúde, de forma a ultrapassar a compreensão hegemônica da racionalidade biológica, e afirmar a abertura ao intercâmbio solidário entre diferentes sistemas culturais em saúde, no sentido de sua complementaridade.

\section{Colaboradores}

MC Nascimento, MT Luz, MI Nogueira e NF Barros participaram na concepção, análise, redação e revisão final do artigo.

\section{Referências}

1. Luz MT, Barros NF, organizadores. Racionalidades Médicas e Práticas Integrativas em Saúde. Estudos teóricos e empíricos. Rio de Janeiro: CEPESC-IMSUERJ, Abrasco; 2012.

2. Santos BS. Toward a New Common Sense: Law, Science and Polictics in the paradigmatic transition. New York: Routledge; 1995.

3. Luz MT. A Arte de Curar versus a Ciência das Doenças. História Social da Homeopatia no Brasil. São Paulo: Dynamis Editorial; 1996.

4. Dupuy JP, Karsenty S. A invasão farmacêutica. Rio de Janeiro: Graal; 1979.

5. Illich I. A expropriação da saúde. Nêmesis da medicina. Rio de Janeiro: Nova Fronteira; 1975.

6. Foucault M. O nascimento da clínica. Rio de Janeiro: Forense Universitária; 1977.

7. Clavreul J. A ordem médica. Poder e impotência do discurso médico. São Paulo: Braziliense; 1983.

8. Nascimento MC. Medicamentos, comunicação e cultura. Cien Saude Colet 2005; 10(Supl.):179-193. 
9. Loyola MA. Médicos e Curandeiros. Conflito Social e Saúde. São Paulo: Difel Difusão Editorial; 1984. (Col. Corpo e Alma do Brasil).

10. Luz MT. Cultura contemporânea e medicinas alternativas: novos paradigmas em saúde no fim do século XX. Physis, Rev Saúde Col 1997, VII(1):13-43.

11. Luz MT. Natural, Racional, Social. Razão Médica e Racionalidade Científica Moderna. 1a Edição. São Paulo: Editora Campus; 1988.

12. Tesser CD, Luz MT. Racionalidades médicas e integralidade. Cien Saude Colet 2008; 13(1):195-206.

13. Luz MT. Novas Práticas em Saúde Coletiva. In: Minayo MCS, Coimbra Júnior CEA, organizadores Críticas e Atuantes: Ciências Sociais e Humanas em Saúde na América Latina. Rio de Janeiro: Ed. Fiocruz; 2005. p. 33-46.

14. Luz HS, Campello MF. Homeopatia. In: Luz MT, coordenador. VI Seminário do Projeto Racionalidades Médicas. Est em Saúde Col 1997; 151:5-35.

15. Luz HS, Campello MF. Homeopatia. In: Luz MT, coordenador. VI Seminário do Projeto Racionalidades Médicas. Est em Saúde Col 1998; 159:9-51.

16. Camargo Júnior KR. Representações de doença, saúde e seu cuidado na clientela de serviços ambulatoriais da rede pública do Rio de Janeiro. Est em Saúde Col 1997; 149:5-13.

17. Luz, D. A medicina tradicional chinesa e os serviços públicos de saúde. Est em Saúde Col 1998; 160:7-42.

18. Canevacci M. Sincretismo: uma exploração das hibridações culturais. São Paulo: Studio Nobel; 1996.

19. Simoni CD, Benevides I, Barros NF. As Práticas Integrativas e Complementares no SUS: realidade e desafios após dois anos de publicação da PNPIC. Rev Bras Saúde da Família 2008; IX:70-76.

20. Azevedo E, Pelicioni MCF. Práticas Integrativas e Complementares de desafios para a educação. Trab. Educ. Saúde 2011/2012; 9(3):361-378.

21. Luz MT. Novos Saberes e Práticas em Saúde Coletiva. São Paulo: Hucitec; 2003.

22. Luz MT. As novas formas de saúde: práticas, representações e valores culturais na sociedade contemporânea. Rev Bras Saúde da Família 2008; IX:8-19.

23. Alves F. Racionalidades Leigas sobre Saúde e Doença Mental - um estudo no Norte de Portugal. In: Fontes B, Fonte EMM, organizadores. Desinstitucionalização, Redes Sociais e Saúde Mental: análise de experiências da reforma psiquiátrica em Angola, Brasil e Portugal. Recife: Ed. Universitária UFPE; 2010. p. 25-69.

24. Alves F. A doença mental nem sempre é doença: racionalidades leigas sobre saúde e doença mental. Porto: Edições Afrontamento; 2011.

25. Silva LF, Alves F. Compreender as racionalidades leigas sobre saúde e doença. Physis Rev Saúde Col 2011; 21(4):1207-1229.
26. Rosa R, Alves MF, Silva LF. Protagonismos alternativos em saúde - contexto teórico de uma pesquisa compreensiva. RECIIS - R. Eletr. De Com. Inf. Inov. Saúde 2011 [acessado 2012 jul 25];5(4):24-31. Disponível em: http://www.reciis.cict.fiocruz.br/index. $\mathrm{php} / \mathrm{reciis} /$ article/view/554

27. Alves F. Recognising madness in other; relativising madness in oneself - from layconcepts to therapeutic itineraries. In Alves F, Jaworski K, Butler S, editors. Madness in plural contexts: crossing borders, linking knowledge. Oxford: E-Book Inter-Disciplinary Press; 2012.

28. Luz MT, Wenceslau LD. A medicina antroposófica como racionalidade médica. In: Luz MT, Barros NF, organizadores Racionalidades Médicas e Práticas Integrativas em Saúde. Estudos teóricos e empíricos. Rio de Janeiro: CEPESC-IMS-UERJ, Abrasco; 2012. p. 185-216.

29. Nascimento MC. De panacéia mística a especialidade médica. A acupuntura na visão da imprensa escrita. Hist. cienc. saude-Manguinhos 1998; 5(1):99-113.

30. Nascimento MC. Acupuntura, Medicina e Interculturalidade. In: Nascimento MC, organizador. As duas faces da montanha: estudos sobre medicina chinesa e acupuntura. São Paulo: Hucitec; 2006. p. 143-177.

31. Conselho Federal de Medicina (CFM). Resolução 1.455/95. Reconhece a Acupuntura como especialidade médica. Diário Oficial da União 1995; 18 set.

32. Nogueira MI. Entre a conversão e o ecletismo: de como médicos brasileiros se tornam "chineses". In: Nascimento MC, organizador. As duas faces da montanha: estudos sobre medicina chinesa e acupuntura. São Paulo: Hucitec; 2006.

33. Nogueira MI. A translação do olhar: da biomedicina à acupuntura. In: Camargo Júnior KR, Nogueira MI, organizadores. Por uma filosofia empírica da atenção à saúde: olhares sobre o campo biomédico. Rio de Janeiro: Editora Fiocruz; 2009.

34. Canclini NG. Consumidores e Cidadãos. Conflitos multiculturais da globalização. Rio de Janeiro: Ed. UFRJ; 1997.

35. Santos BS, organizador. Semear outras soluções: os caminhos da biodiversidade e dos conhecimentos rivais. Porto: Afrontamento; 2004

36. Santos BS. Um discurso sobre as ciências. $7^{\text {a }}$ Edição. São Paulo: Ed. Cortez; 2010.

37. Meneses MP. Epistemologias do Sul. Rev Crítica de Ciênc Sociais 2008; 80:5-10.

Artigo apresentado em 11/06/2012

Aprovado em 26/07/2012

Versão final apresentada em 08/08/2012 